\title{
Spectral Studies of UV and Solar Photocatalytic Degradation of AZO Dye and Textile Dye Effluents Using Green Synthesized Silver Nanoparticles
}

\author{
R. Mariselvam, ${ }^{1}$ A. J. A. Ranjitsingh, ${ }^{2}$ P. Mosae Selvakumar, ${ }^{3}$ \\ Abdullah A. Alarfaj, ${ }^{4}$ and Murugan A. Munusamy ${ }^{4}$ \\ ${ }^{1}$ Department of Chemistry, Sri Paramakalyani College, Alwarkurichi, Tirunelveli, Tamil Nadu 627412, India \\ ${ }^{2}$ J.P. College of Arts and Science, Ayikudi, Tamil Nadu 627852, India \\ ${ }^{3}$ Department of Chemistry, Karunya University, Coimbatore, Tamil Nadu 641114, India \\ ${ }^{4}$ Department of Botany and Microbiology, College of Science, King Saud University, Riyadh 11451, Saudi Arabia \\ Correspondence should be addressed to A. J. A. Ranjitsingh; honeyselvam01@gmail.com
}

Received 29 December 2015; Accepted 27 April 2016

Academic Editor: Concepción López

Copyright (C) 2016 R. Mariselvam et al. This is an open access article distributed under the Creative Commons Attribution License, which permits unrestricted use, distribution, and reproduction in any medium, provided the original work is properly cited.

\begin{abstract}
The photocatalytic degradation of the chemical dye AZO and dye effluents in different time duration has been investigated using biologically synthesized silver nanoparticles. Dye industry effluents and AZO dye undergo degradation to form harmless intermediate and colourless products following irradiation by UV and solar light in the presence of green synthesized silver nanoparticles. The degree of degradation was tested under the experimental conditions such as $\mathrm{P}^{\mathrm{H}}$, temperature, and absorbance of the dye in UV and solar light was measured. The degradation was higher in the UV light source than in the solar light source. Green synthesized silver nanoparticles in the UV light source were found to expedite the dye degradation process.
\end{abstract}

\section{Introduction}

The emission of effluents from textile industries has been a major concern of the modern world, due to the great pollution that these effluents promote on the water resources [1]. In the synthetic dyes released in effluents from textile industries, AZO dye is one of the more detrimental classes because of its high persistent nature in the aquatic environment, due to its chemical compositions, involving aromatic rings, azoic linkages, and amino groups [2]. The dye industry effluents are a major problem worldwide. The dye industry effluents not only disturb the aquatic ecosystem but also the biota and human beings.

The dyes are used to modify the colour characteristics of different substrates, such as fibre products, fabric, leather, plastic, wood products, and paper. The dyes were extracted from natural sources, mainly from animals and plant materials, and used much before the nineteenth century [3]. After the nineteenth century the natural dyes were replaced by synthetic dyes. Every day new synthetic dyes are developed for new colours and this eliminates the use of natural dye. These synthetic dyes are inorganic substances to pollute the water bodies. The dye effluent can induce oxidative stress [4], mutagenic activity [5-8], and carcinogenic activity and it can also generate DNA adducts and so forth in living organisms. Nowadays, the dyestuffs and textile effluents were treated using various physical, chemical, and biological methods [9-14]. In the dye effluents treatment, the use of green synthesized nanoparticles is less understood. So in the present study silver nanoparticles synthesized using plant material were tested to treat dye effluents.

\section{Materials and Methods}

2.1. Synthesis and Characterization of Silver Nanoparticles (AgNPs). The green synthesized silver nanoparticles were 


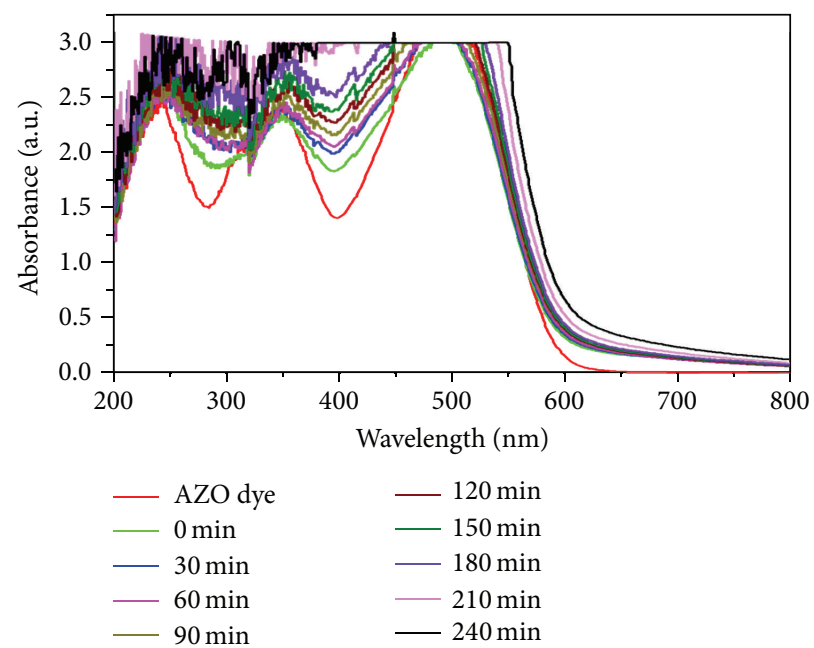

(a)
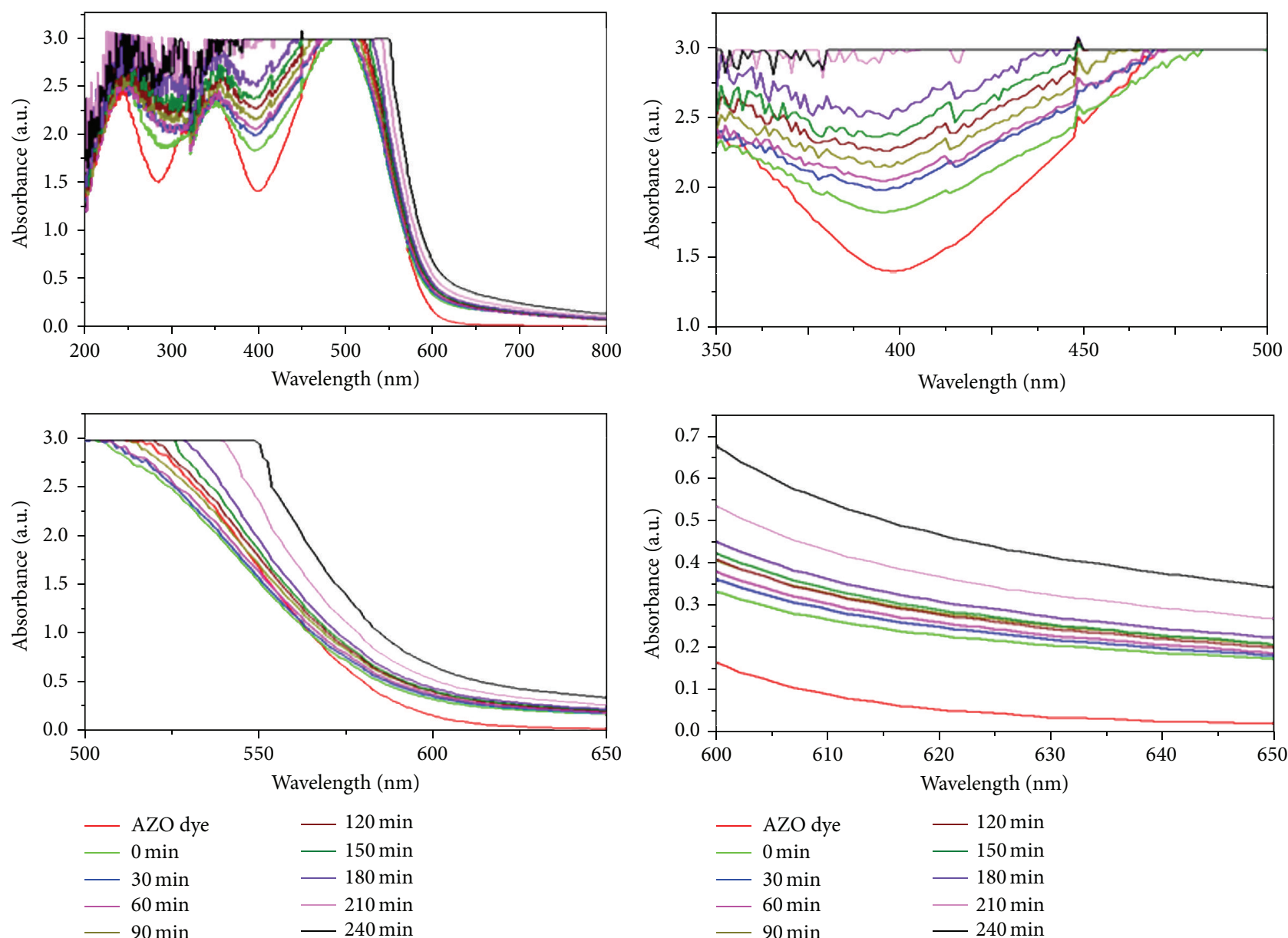

(b)

FIGURE 1: Solar light irradiated AZO dye degradation using green synthesized AgNPs as photocatalyst.

prepared using the crude extract of coconut tree inflorescence fraction (EA : M $(40: 60))$ as per technology developed [15]. These synthesized nanoparticles were $22 \mathrm{~nm}$, spherical sized particles. The characteristics of AgNPs were studied using $\mathrm{UV} /$ visible spectroscopy, FTIR, and TEM assays.
2.2. Preparation of AZO Dye. The commercially available AZO dye was purchased from Merck, India. One gram of AZO dye was dissolved in $1000 \mathrm{~mL}$ of double distilled water carefully in dark bottles. The dye concentration was $0.1 \%$. The prepared dye was used for further studies. 


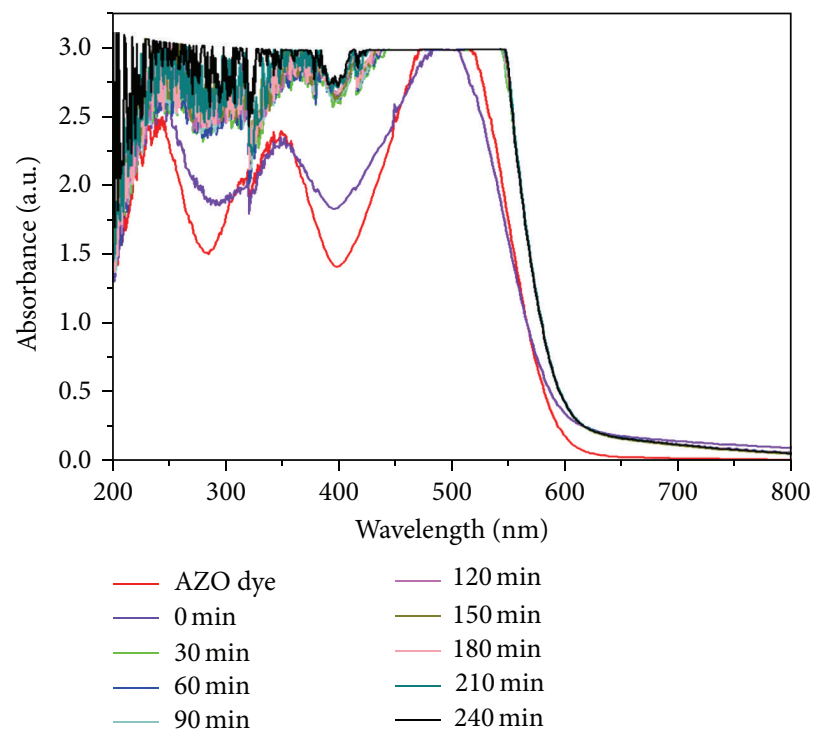

(a)
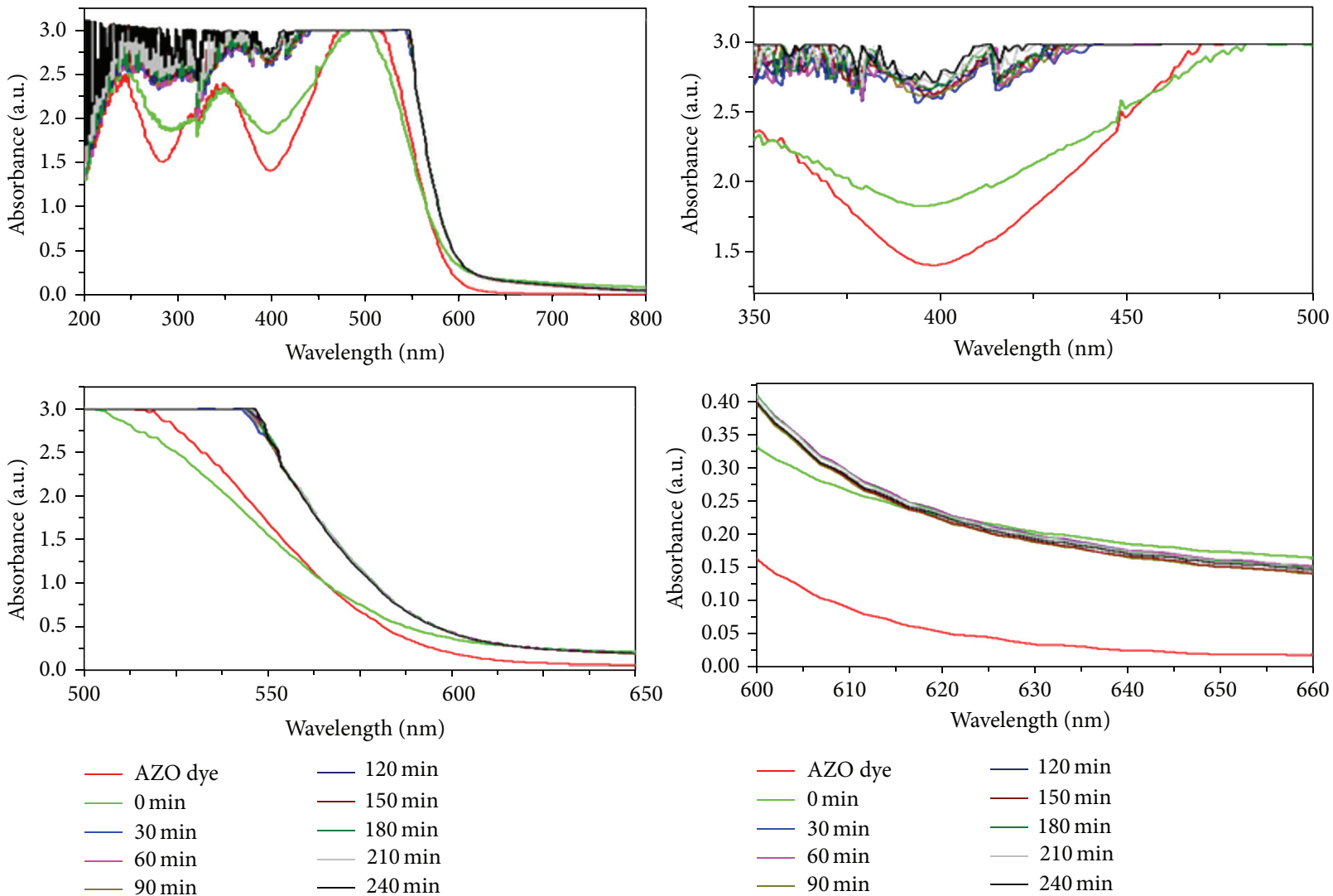

(b)

FIGURE 2: Monochromatic UV light irradiated AZO dye degradation using green synthesized AgNPs as the photocatalyst.

2.3. Collection of Dye Industry Effluents. The textile mill effluent was collected from the sewage tank in a textile factory in Tiruppur, Tamil Nadu, India.

2.4. Photocatalytic Based Degradation. The photocatalytic degradation of AZO dye and textile industry effluents was investigated using green synthesized silver nanoparticles as a photocatalyst under solar light and UV light. The dye degradation was tested by UV/visible double beam spectroscopy 2203 and kinetic measurement was performed at room temperature for UV radiated dye degradation and at outside room temperature for solar radiation. The concentration of the dye was (Optical Density) measured at 200-1000 nm wavelength. The progress of the photocatalytic 

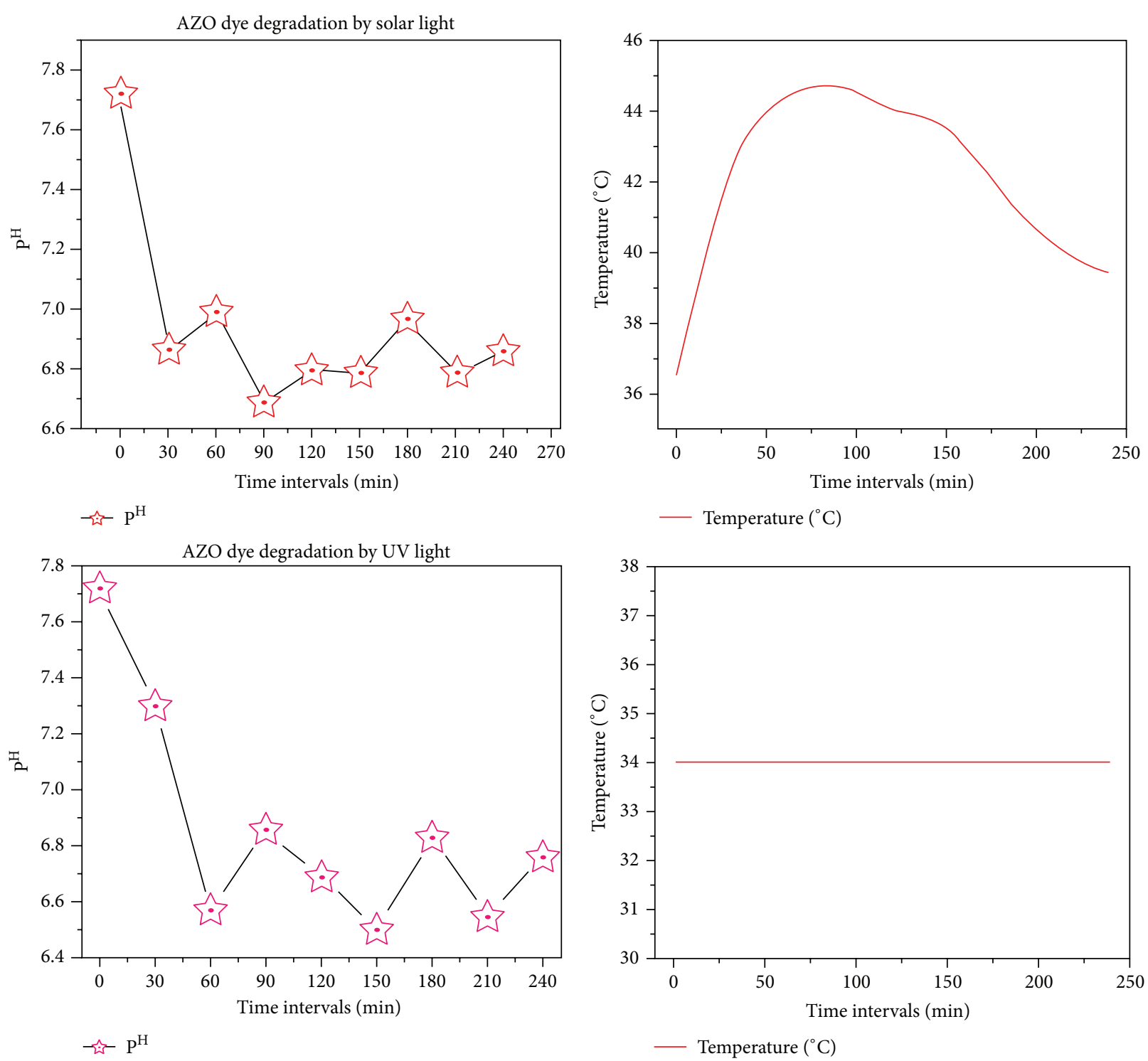

Figure 3: $\mathrm{P}^{\mathrm{H}}$ and temperature variation ranges in different time intervals of AZO dye degradation.

reaction was observed by recording optical density at regular time intervals. The temperature and $\mathrm{P}^{\mathrm{H}}$ were also measured at regular time intervals.

\section{Result and Discussion}

AZO dyes are compounds characterized by the presence of one or more AZO groups $(-\mathrm{N}=\mathrm{N}-)$ [2]. This was confirmed by the presence of two absorption bands at $568-737 \mathrm{~nm}$ and another at $404-475 \mathrm{~nm}$. These two absorption bands are responsible for $n \rightarrow \pi^{*}$ electron transition. The effluents have two major absorption peaks and were noted at $227 \mathrm{~nm}$ and $214 \mathrm{~nm}$. These two peak values always correspond with $n \rightarrow \pi^{*}$ electron transition.

3.1. Photodegradation Process for AZO Dye. The photodegradation process was carried out under solar and UV light irradiation using green synthesized silver nanoparticles as photocatalysts. The absorption spectra of AZO dye (Figures $1(\mathrm{a})$ and $1(\mathrm{~b})$ ) degradation under solar light irradiation were observed regularly at time intervals. The solar and UV light irradiation, the intimacy between dye molecules and a semiconductor material, and the presence of oxygen are indispensable for an efficient photosensitized degradation reaction.

The results were shown in Figures 1(a), 1(b), 2(a), and 2(b). The excitation of AZO molecules also depends on the $\mathrm{P}^{\mathrm{H}}$ and temperature. The excited molecules were absorbed by the Ag nanoparticles. It was confirmed by the absorption spectrum at the regular time intervals (Figures 1(b) and 2(b)). The time taken for dye degradation and $\mathrm{P}^{\mathrm{H}}$ changed irregularly (Figure 3). The efficacy of light source has changed the electron transition in AZO molecules. 


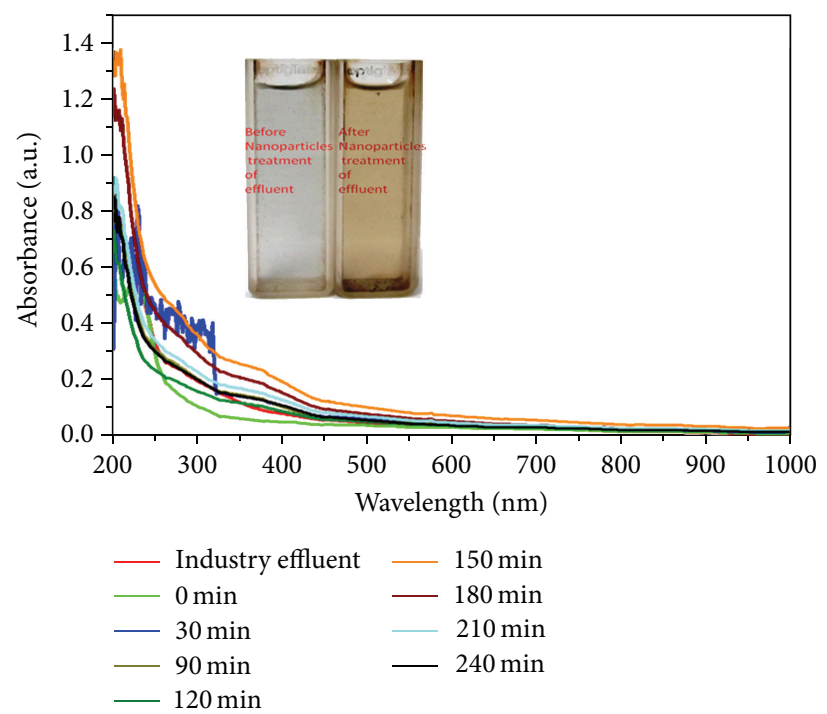

(a)
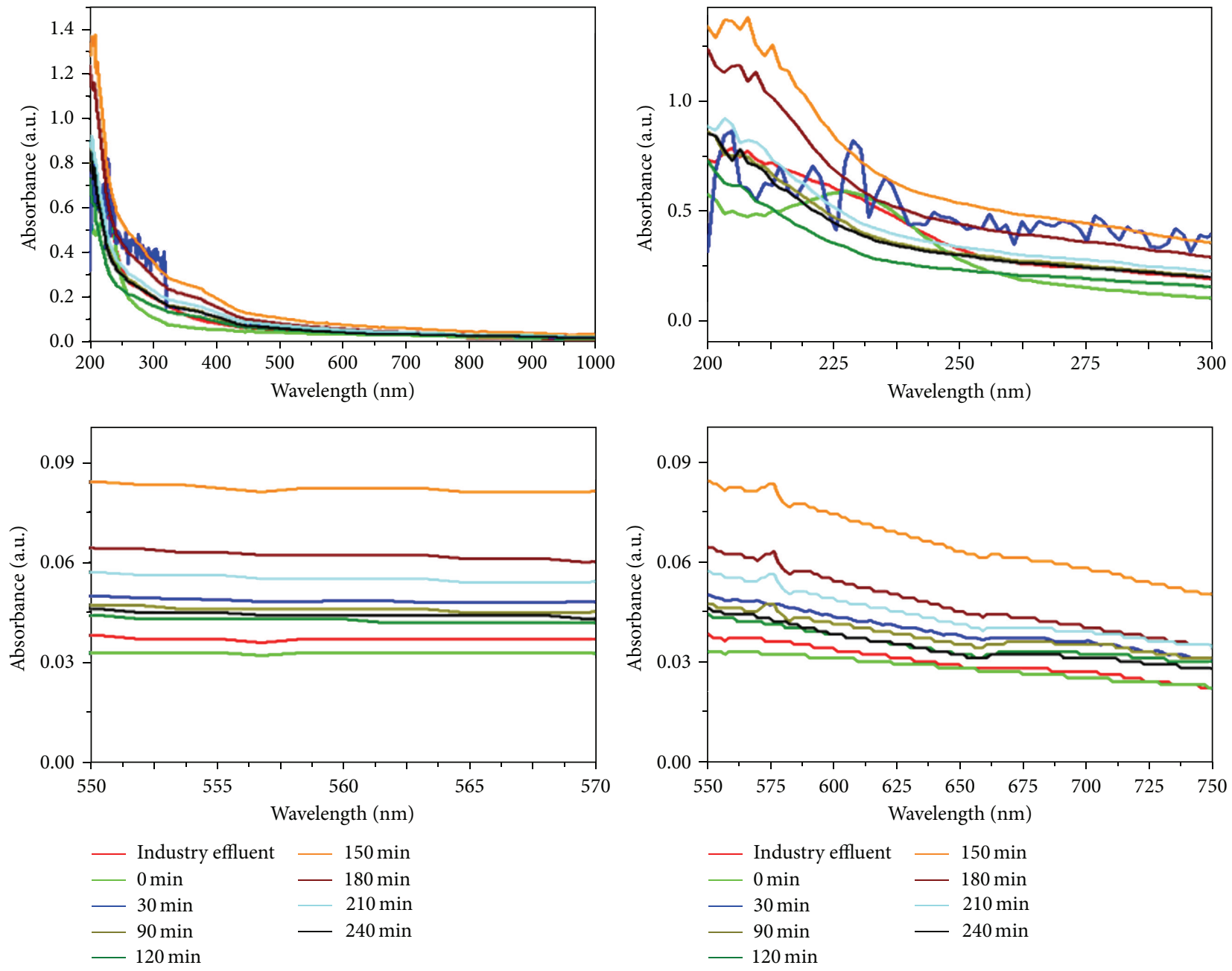

(b)

FIGURE 4: Solar light irradiated industry effluents using green synthesized AgNPs as the photocatalyst. 


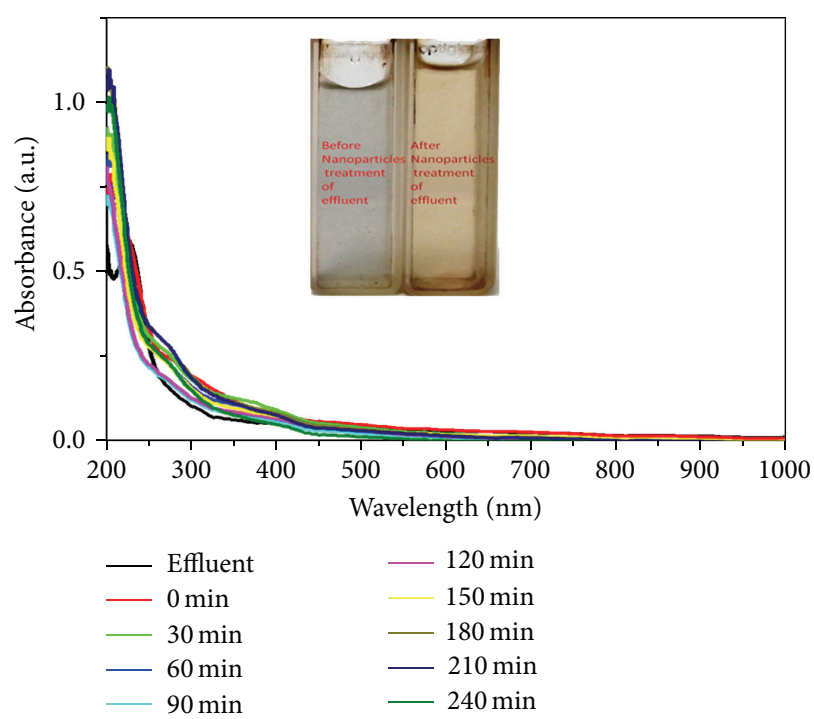

(a)
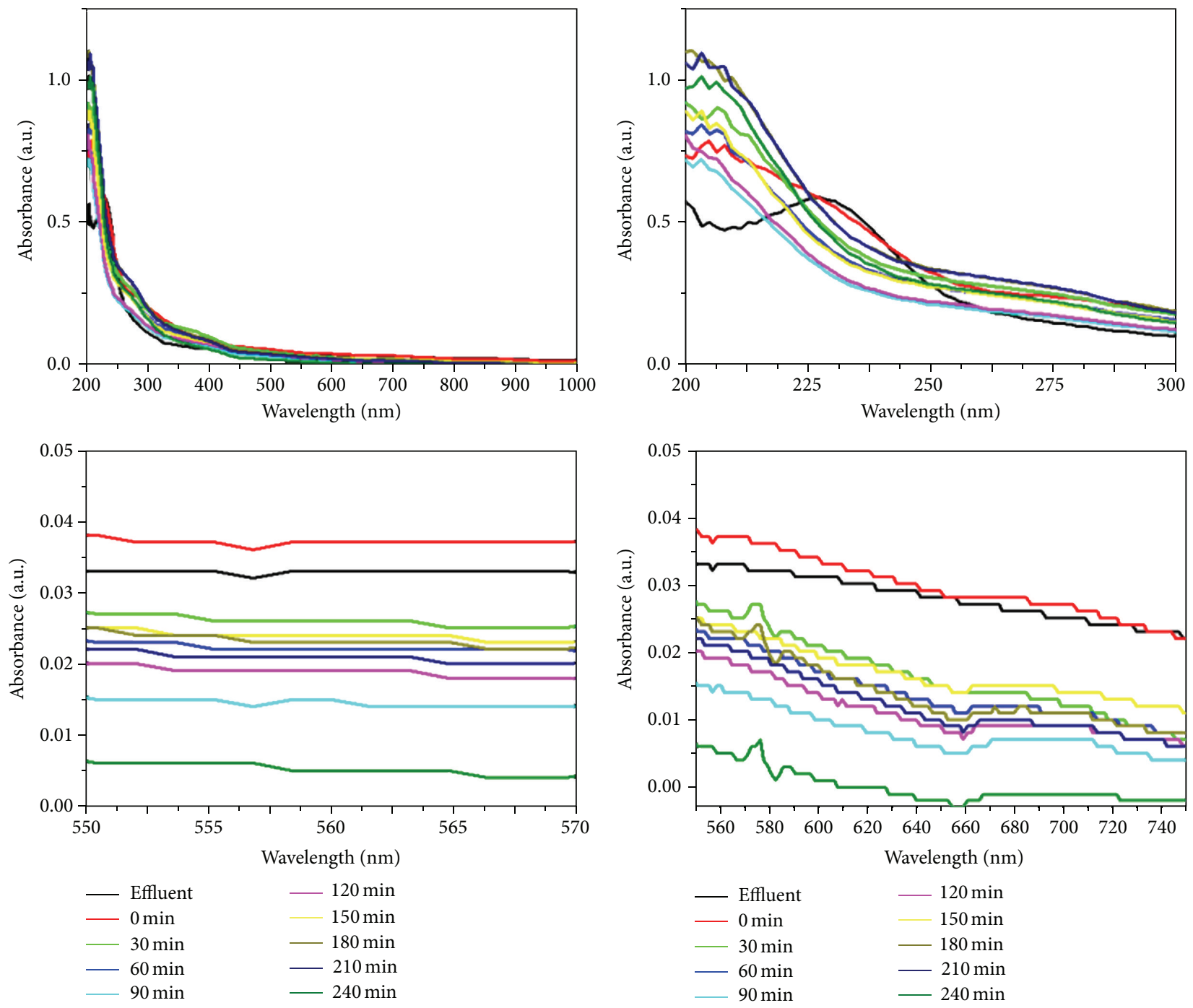

(b)

FIGURE 5: Monochromatic UV light irradiated industry effluent using green synthesized AgNPs as the photocatalyst. 

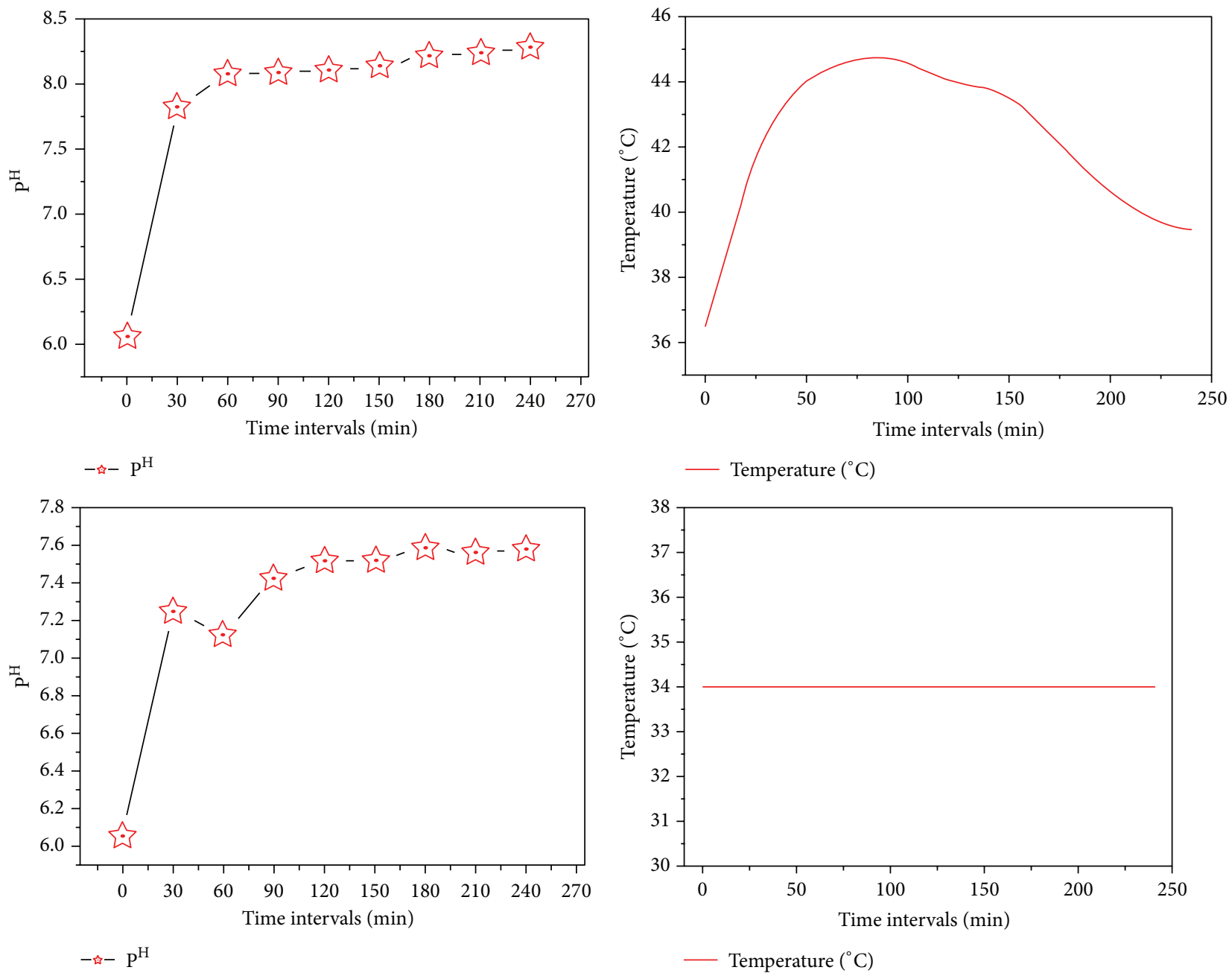

-合- $\mathrm{P}^{\mathrm{H}}$

— Temperature $\left({ }^{\circ} \mathrm{C}\right)$

FIGURE 6: $\mathrm{P}^{\mathrm{H}}$ and temperature variation ranges in different time intervals of industry effluent degradation.

As the dye molecules were largely seen on the sample surface, the degradation reaction proceeds predominantly through the monochromatic UV light irradiation as reflected by the drastic shift in absorption spectra as shown in Figures 2(a) and 2(b). The comparison of solar and UV light irradiation showed that the UV light has degraded the AZO dyes more effectively than the solar sources.

3.2. Photodegradation Process for Textile Industry Effluents. The photodegradation process was carried out under solar and ultraviolet irradiation using green synthesized silver nanoparticles as the photocatalyst. Figures 5(a) and 5(b) indicate the absorption spectra of effluent degradation under solar light irradiation. The solar light irradiation induced the electrons (nanoparticles) and is excited from $n \rightarrow \pi^{*}$ electron transition. The absorption rate at regular time intervals and the $\mathrm{P}^{\mathrm{H}}$ sequentially increased (Figure 6) based on the light intensity (light energy).

In this reaction also the solar and UV light irradiation, the intimacy between the dye molecule's and a semiconductor material, and the presence of oxygen are indispensable for an efficient photosensitized degradation reaction.

The results shown in Figures 4(a) and 5(a) show the excitation of dye molecule's in the effluents. The excitation of electrons depends on $\mathrm{P}^{\mathrm{H}}$, light intensity (light energy), and temperature. The excited electrons bound to the dye molecules. Then the effluent got changed in their physical, chemical, and biological properties and binding capability. This was confirmed by the absorption spectrum at the regular time intervals (Figures $4(\mathrm{~b})$ and $5(\mathrm{~b})$ ). $\mathrm{P}^{\mathrm{H}}$ got increased with the increase of the duration of dye degradation (Figure 6).

\section{Conclusion}

Presence of AZO dyes and other dyes in the textile mill effluents threatens the aquatic food chain. In order to degrade the dyes, UV and solar light irradiation in the presence of green synthesized silver nanoparticles were tested. The presence of green synthesized AgNPs promoted the degradation fast. Hence the coconut tree inflorescence extract mediated silver 
nanoparticles were found to enhance the photocatalytic dye degradation effectively.

\section{Competing Interests}

The authors declare that there is no conflict of interests regarding the publication of this paper.

\section{Acknowledgments}

The authors extend their sincere thanks to the Deanship of Scientific Research at King Saud University for its funding of this research through the Research Group Project no. RG1435-065.

\section{References}

[1] P. Ratna, "Pollution due to synthetic dyes toxicity \& carcinogenicity studies and remediation," International Journal of Environmental Sciences, vol. 3, no. 3, pp. 940-955, 2012.

[2] N. Puvaneswari, J. Muthukrishnan, and P. Gunasekaran, "Toxicity assessment and microbial degradation of azo dyes," Indian Journal of Experimental Biology, vol. 44, no. 8, pp. 618-626, 2006.

[3] R. Mari selvam, K. Kalirajan, and A. J. A. Ranjit Singh, "Antimicrobial activity of turmeric natural dyes against different bacterial strains," Journal of Applied Pharmaceutical Science, vol. 2, no. 6, pp. 210-212, 2012.

[4] K. A. Amin, H. Abdel Hameid, and A. H. Abd Elsttar, "Effect of food azo dyes tartrazine and carmoisine on biochemical parameters related to renal, hepatic function and oxidative stress biomarkers in young male rats," Food and Chemical Toxicology, vol. 48, no. 10, pp. 2994-2999, 2010.

[5] M. S. Tsuboy, J. P. F. Angeli, M. S. Mantovani, S. Knasmüller, G. A. Umbuzeiro, and L. R. Ribeiro, "Genotoxic, mutagenic and cytotoxic effects of the commercial dye CI Disperse Blue 291 in the human hepatic cell line HepG2," Toxicology in Vitro, vol. 21, no. 8, pp. 1650-1655, 2007.

[6] S. J. Biswas and A. R. Khuda-Bukhsh, "Cytotoxic and genotoxic effects of the azo-dye p-dimethylaminoazobenzene in mice: a time-course study," Mutation Research/Genetic Toxicology and Environmental Mutagenesis, vol. 587, no. 1-2, pp. 1-8, 2005.

[7] K.-M. Wollin and B.-D. Görlitz, "Comparison of genotoxicity of textile dyestuffs in Salmonella mutagenicity assay, in vitro micronucleus assay, and single cell gel/comet assay," Journal of Environmental Pathology, Toxicology and Oncology, vol. 23, no. 4, pp. 267-278, 2004.

[8] A. Garg, K. L. Bhat, and C. W. Bock, "Mutagenicity of aminoazobenzene dyes and related structures: a QSAR/QPAR investigation," Dyes and Pigments, vol. 55, no. 1, pp. 35-52, 2002.

[9] R. G. Saratale, G. D. Saratale, J. S. Chang, and S. P. Govindwar, "Bacterial decolorization and degradation of azo dyes: a review," Journal of the Taiwan Institute of Chemical Engineers, vol. 42, no. 1, pp. 138-157, 2011.

[10] A. Anastasi, V. Prigione, and G. C. Varese, "Industrial dye degradation and detoxification by basidiomycetes belonging to different eco-physiological groups," Journal of Hazardous Materials, vol. 177, no. 1-3, pp. 260-267, 2010.

[11] F. Deniz and S. D. Saygideger, "Equilibrium, kinetic and thermodynamic studies of Acid Orange 52 dye biosorption by
Paulownia tomentosa Steud. leaf powder as a low-cost natural biosorbent," Bioresource Technology, vol. 101, no. 14, pp. 5137$5143,2010$.

[12] G. S. Ghodake, A. A. Talke, J. P. Jadhav, and S. P. Govindwar, "Potential of Brassica juncea in order to treat textile-effluentcontaminated sites," International Journal of Phytoremediation, vol. 11, no. 4, pp. 297-312, 2009.

[13] A. N. Kagalkar, U. B. Jagtap, J. P. Jadhav, V. A. Bapat, and S. P. Govindwar, "Biotechnological strategies for phytoremediation of the sulfonated azo dye Direct Red 5B using Blumea malcolmii Hook," Bioresource Technology, vol. 100, no. 18, pp. 4104-4110, 2009.

[14] Y.-H. Lin and J.-Y. Leu, "Kinetics of reactive azo-dye decolorization by Pseudomonas luteola in a biological activated carbon process," Biochemical Engineering Journal, vol. 39, no. 3, pp. 457467, 2008.

[15] R. Mariselvam, A. J. A. Ranjitsingh, A. Usha Raja Nanthini, K. Kalirajan, C. Padmalatha, and P. Mosae Selvakumar, "Green synthesis of silver nanoparticles from the extract of the inflorescence of Cocos nucifera (Family: Arecaceae) for enhanced antibacterial activity," Spectrochimica Acta-Part A: Molecular and Biomolecular Spectroscopy, vol. 129, pp. 537-541, 2014. 

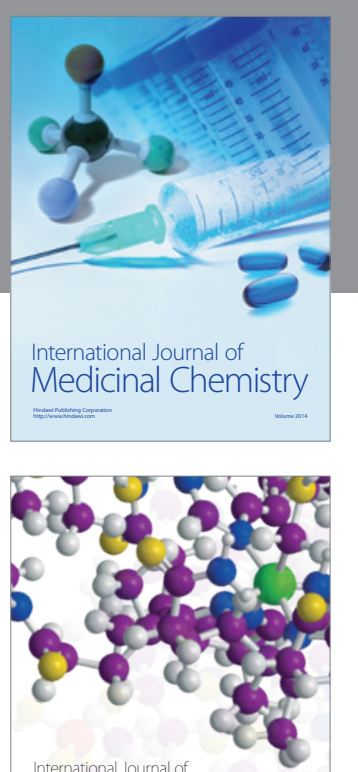

Carbohydrate Chemistry

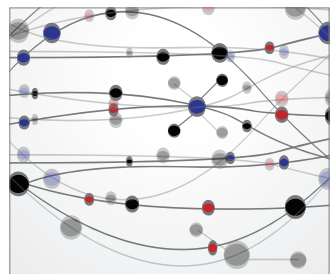

The Scientific World Journal
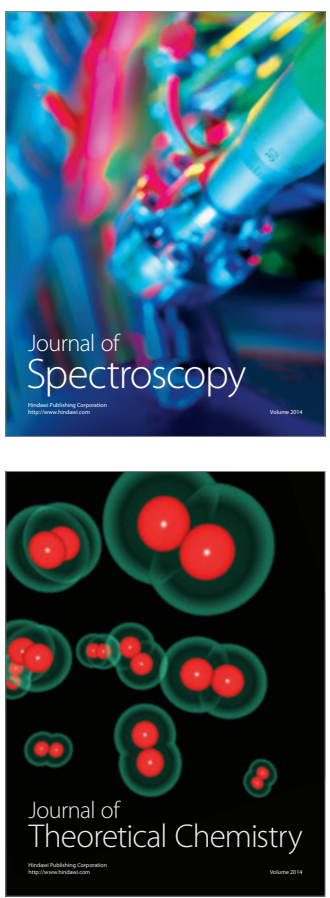
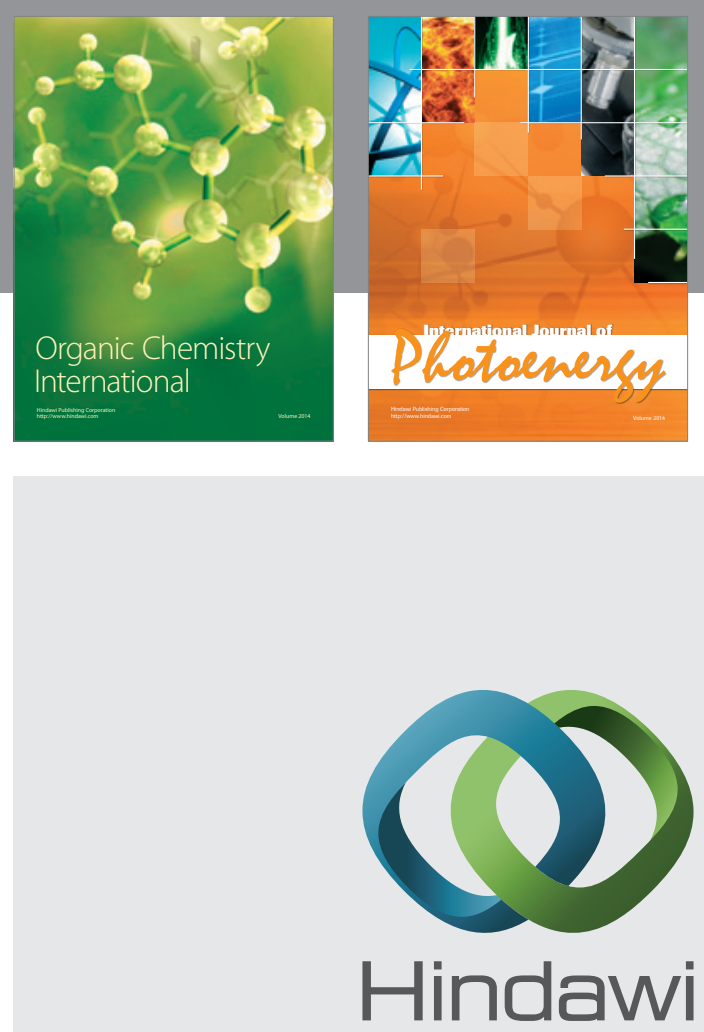

Submit your manuscripts at

http://www.hindawi.com

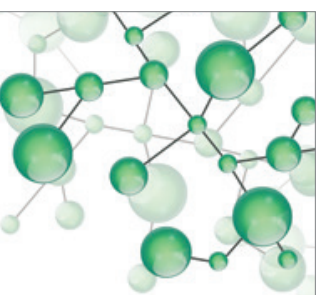

International Journal of

Inorganic Chemistry

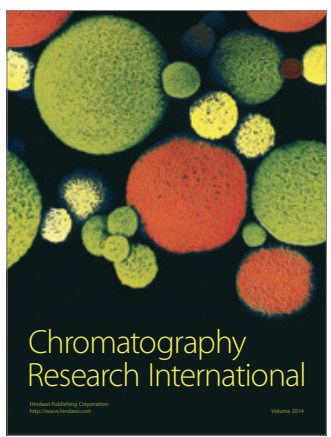

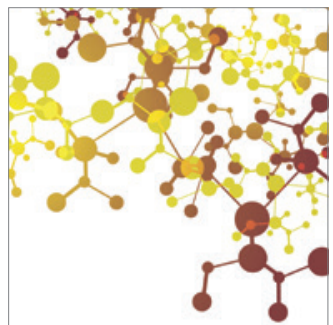

Applied Chemistry
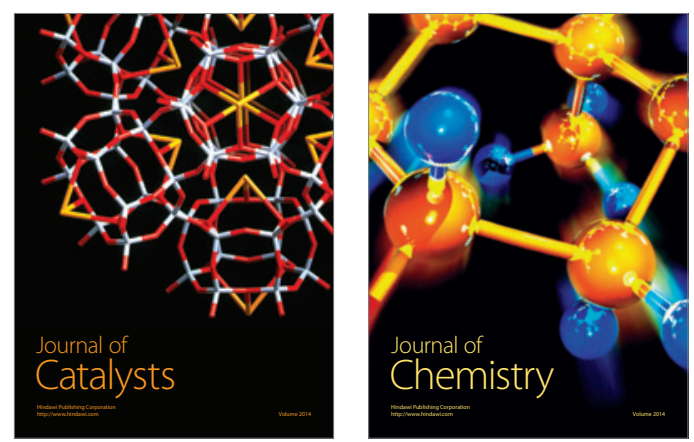
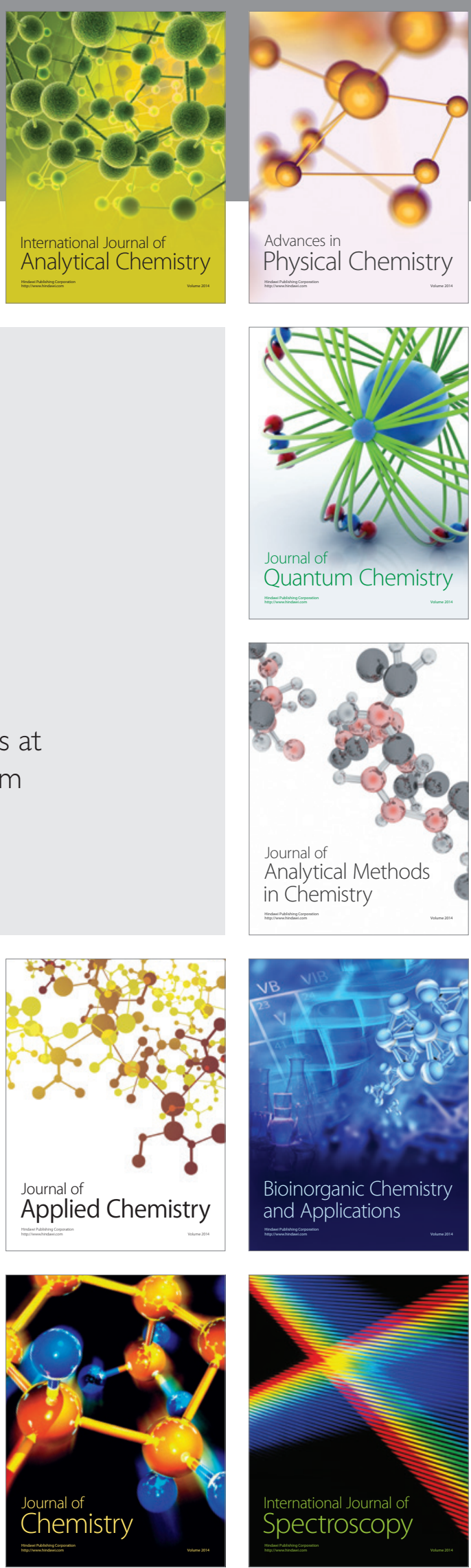